\title{
The Method of Calculation of Load of a Group of Complexes With the Devil-Pilot Aircraft, When Conducting Search and Rescue Operations
}

\author{
Alexei I. Tishchenko* \\ Military Education and Research Centre of Military-Air Forces \\ "Military-Air Academy \\ Named After Professor N.E. Zhukovsky and Yu.A. Gagarin» \\ 54a Starykh Bolshevikov Str., Voronezh, 394064, Russia
}

Received 17.07.2018, received in revised form 12.09.2018, accepted 12.10.2018

The article considers the mathematical model of calculation of the number of departures of a group of complexes with unmanned aerial vehicles in search of people to justify the decision of the group leadership to end or continue search and rescue operations.

Keywords: complex with unmanned aerial vehicle, search of people, the method of sequential analysis, decision making, search and rescue operations.

\section{Методика расчета нагрузки отряда комплексов \\ с беспилотными летательными аппаратами \\ при проведении поисково-спасательных работ}

А.И. Тищенко

Военный учебно-научный иентр Военно-воздушных сил «Военно-воздушная академия имени профессора Н.Е. Жуковского и Ю.А. Гагарина» Россия, 394064, Воронеж, ул. Старых Большевиков, 54 а

В статье рассматривается математическая модель расчета количества вылетов отряда комплексов с беспилотныли летательными аппаратами на поиск людей с иелью обоснования

(C) Siberian Federal University. All rights reserved

This work is licensed under a Creative Commons Attribution-NonCommercial 4.0 International License (CC BY-NC 4.0).

* Corresponding author E-mail address: aleksei.tishenko@yandex.ru 
принятия решения группь руководства по прекращению или продолжению поисковоспасательных работ.

Ключевые слова: комплекс с беспилотным летательным аппаратом, поиск людей, метод последовательного анализа, принятие решения, поисково-спасательные работы.

\section{Введение}

Поиск потерявшихся людей - одно из перспективных направлений использования комплексов с беспилотными летательными аппаратами (КБЛА). Они широко используются в Министерстве Российской Федерации по делам гражданской обороны, чрезвычайным ситуациям и ликвидации последствий стихийных бедствий, в Министерстве обороны Российской Федерации, в Министерстве внутренних дел Российской Федерации и в ряде других ведомств на этапе принятия решения о развертывании и приведения в действие широкомасштабных поисковоспасательных работ.

Если в процессе поиска обнаружение потерявшихся людей произошло, то все экономические издержки, связанные со спасательными работами, оправданны. Если же обнаружение не произошло, то возникает вопрос, как долго необходимо вести поисковые вылеты КБЛА для принятия решения о прекращении поисково-спасательных работ.

Целью работы является разработка на основе метода последовательного анализа [1] математического аппарата расчета нагрузки отряда КБЛА при выполнении поисково-спасательных работ, связанных с поиском потерявшихся людей.

\section{Постановка задачи}

Пусть выполняется поисково-спасательная работа, связанная с поиском потерявшихся людей в заданном труднодоступном районе. Основным источником информации о наличии или отсутствии людей в заданном районе служит КБЛА [2]. После каждого вылета КБЛА на основе полученной информации руководитель работ принимает решение о продолжении или прекращении поисково-спасательных мероприятий. В случае обнаружения пострадавших полеты КБЛА прекращаются и выполняется комплекс мероприятий по их спасению. Если обнаружение не произошло, то может быть два варианта решения. Первый вариант - вылет КБЛА прекратить, спасательные работы закончить. Второй вариант - вылет КБЛА с целью получения дополнительной информации для принятия окончательного решения продолжить, силы и средства спасения перевести в дежурную готовность. В этом случае возникает необходимость определения достаточного количества вылетов КБЛА на воздушную разведку района поиска, при котором будет объективно обоснован переход от второго варианта решения руководителя к первому.

\section{Математическая модель расчета количества вылетов комплекса с беспилотным летательным аппаратом на поиск пропавших людей}

Обнаружение КБЛА пропавших людей в труднодоступном районе носит случайный характер в силу случайности процесса обнаружения оптико-электронным оборудованием КБЛА различных объектов, в том числе и людей [3]. Штаб поисково-спасательных работ при разработке предложений руководителю использует статистические оценки вероятности обнару- 
жения КБЛА пропавших людей. Поэтому предложения штаба, а следовательно, и решение руководителя носят случайный характер и вырабатываются на основе двух гипотез: $H_{1}$ - полеты КБЛА прекратить, силам и средствам спасения приступить к эвакуации пропавших людей; $\mathrm{H}_{2}$ - полеты КБЛА прекратить, комплекс мероприятий поисково-спасательных работ в районе поиска прекратить. Суждение о реализации одной из гипотез осуществляется на основе сравнения статистической оценки вероятности обнаружения КБЛА в ходе воздушной разведки пропавших людей с пороговым значением этой же характеристики. Пороговое значение вероятности обнаружения может содержать ошибку из-за ограниченного числа вылетов КБЛА на поиск пропавших людей и случайного характера их результатов. В силу этого в окрестности точки порогового значения вероятности обнаружения возникает зона неопределенности. Размер зоны зависит от количества вылетов КБЛА на поиск пропавших людей (количества наблюдений) и вероятности обнаружения пропавших полезной нагрузкой комплекса (техническими характеристиками средств наблюдения комплекса). Для реализации метода последовательного анализа при решении поставленной задачи необходимо знать допустимую величину этой зоны. Если статистическая оценка вероятности лежит в пределах зоны неопределенности, то невозможно принять решение о реализации одной из гипотез $-H_{1}$ или $H_{2}$. В этих случаях для принятия решения необходимо проводить дополнительные воздушные разведки КБЛА по поиску пропавших людей.

Статистическая оценка вероятности обнаружения КБЛА пропавших людей будет иметь центр рассеивания - неизвестную величину $p_{\phi}$ - фактическая вероятность обнаружения КБЛА потерявшихся людей, связанную с оценкой соотношением $p_{\phi} \pm 3 \sigma_{p}$, где $\sigma_{p}$ - среднее квадратическое отклонение оценки относительно фактической вероятности обнаружения КБЛА потерявшихся людей. В результате появляется дополнительный источник ошибки принятия решения, связанный с тем, что зоны рассеивания и неопределенности накладываются друг на друга. Возникают ошибки первого рода $\alpha$ (вместо правильной гипотезы $H_{l}$ будет принята неверная гипотеза $H_{2}$ ) и второго рода $\beta$ (вместо правильной гипотезы $H_{2}$ будет принята неверная гипотеза $H_{1}$ ). Принять обоснованное решение о наличии гипотез $H_{1}$ или $H_{2}$ в этом случае можно только тогда, когда установлены допустимые вероятности совершить ошибки первого и второго родов.

Таким образом, для решения задачи необходимо штабу поисково-спасательных работ во главе с руководителем установить:

зону принятия гипотезы $H_{2}$; если оценка вероятности обнаружения КБЛА потерявшихся людей лежит правее правой границы зоны неопределенности $p_{2}$, полеты КБЛА прекращаются;

зону принятия гипотезы $H_{l}$; если оценка вероятности обнаружения КБЛА потерявшихся людей лежит левее левой границы зоны неопределенности $p_{1}$, полеты КБЛА прекращаются;

зону проведения дополнительного вылета КБЛА на поиск потерявшихся людей, если оценка вероятности обнаружения потерявшихся людей лежат в пределах зоны неопределенности $\left[p_{1}, p_{2}\right]$;

вероятность ошибки первого рода $\alpha$;

вероятность ошибки второго рода $\beta$.

Пусть проведено $n$ воздушных разведок КБЛА на поиск потерявшихся людей. Из них в $m$ случаях потерявшиеся люди были обнаружены, а в $n-m$ случаях потерявшиеся люди не были обнаружены. Обозначим через $p$ вероятность неблагоприятного исхода поиска людей КБЛА.

$$
-825-
$$




\begin{tabular}{|c|c|c|}
\hline$B$ & \multirow{3}{*}{$\begin{array}{c}\text { Полеты КБЛА на поиск } \\
\text { потерявиихся людей } \\
\text { продолжсть }\end{array}$} & $A$ \\
\hline $\begin{array}{l}\text { Полеты КБЛА прекратить, } \\
\text { силаи и средствам спасения } \\
\text { приступить к эвакуачии } \\
\text { пропавиих людей }\end{array}$ & & $\begin{array}{l}\text { Полеты КБЛА прекратить, } \\
\text { комплекс мероприятий } \\
\text { поисково-спасательных } \\
\text { работ в районе поиска } \\
\text { прекратить }\end{array}$ \\
\hline $\begin{array}{l}\text { Допустииая вероятность } \\
\text { оиибки I-го рода равна } \alpha\end{array}$ & & $\begin{array}{l}\text { Дотустимая вероятность } \\
\text { оиибки 2-го рода равна } \beta\end{array}$ \\
\hline
\end{tabular}

Рис. 1. К правилу принятия решения руководителем поисково-спасательных работ после n-го вылета КБЛА

Fig. 1. To the rule of decision-making by the head search and rescue operations after the n-th departure of the KBLA

Тогда вероятность сочетания исходов в $n$ воздушных разведок КБЛА будет определяться выражением

$$
P_{n}(p)=p^{m}(1-p)^{n-m}
$$

где $p=\frac{m}{n}-$ вероятность неблагоприятного поиска людей КБЛА.

Для принятия гипотез введем критерий правдоподобия $\mu$ :

$$
\mu=\frac{P_{n}\left(p_{2}\right)}{P_{n}\left(p_{1}\right)}=\frac{p_{2}^{m}\left(1-p_{2}\right)^{n-m}}{p_{1}^{m}\left(1-p_{1}\right)^{n-m}} .
$$

В этом случае правило принятия решения руководителем поисково-спасательных работ после $n$-го вылета КБЛА будет иметь вид (рис. 1):

при $\mu \geq A$ рекомендуется полеты КБЛА прекратить, комплекс мероприятий поисковоспасательных работ в районе поиска прекратить;

при $\mu \leq B$ рекомендуется полеты КБЛА прекратить, силам и средствам спасения приступить к эвакуации пропавших людей;

при $B<\mu<A$ следует провести $(n+1)$-й полет КБЛА для поиска потерявшихся людей.

Выразим границу зон $A$ и $B$ через вероятности $\alpha$ и $\beta$. Спасательные работы будут целесообразны в двух случаях:

1. Фактическая вероятность обнаружения потерявшихся людей КБЛА больше граничного условия $p_{2}$, и не будет совершена ошибка второго рода. Вероятность не совершить эту ошибку и в целом принять правильную гипотезу $H_{2}$ равна $1-\beta$.

2. Фактическая вероятность обнаружения потерявшихся людей КБЛА меньше граничного условия $p_{1}$, но будет совершена ошибка первого рода. Вероятность совершить эту ошибку и в целом принять ошибочную гипотезу $H_{2}$ равна $\alpha$.

Тогда $\mu$ примет вид

$$
\mu=\frac{1-\beta}{\alpha} \geq A
$$

Спасательные работы будут нецелесообразны также в двух случаях:

$$
-826-
$$


1. Фактическая вероятность обнаружения потерявшихся людей КБЛА меньше граничного условия $p_{1}$, и не будет совершена ошибка первого рода. Вероятность не совершить эту ошибку и в целом принять правильную гипотезу $H_{l}$ равна $1-\alpha$.

2. Фактическая вероятность обнаружения потерявшихся людей КБЛА больше граничного условия $p_{2}$, но будет совершена ошибка второго рода. Вероятность совершить эту ошибку и в целом принять ошибочную гипотезу $H_{l}$ равна $\beta$.

Тогда $\mu$ примет вид

$$
\mu=\frac{\beta}{1-\alpha} \leq B
$$

Условие целесообразности проведения дополнительного полета КБЛА для поиска пропавших людей запишем в виде

$$
\frac{\beta}{1-\alpha}<\mu<\frac{1-\beta}{\alpha}
$$

Выразим параметры $A$ и $B$ через $\alpha$ и $\beta$. Получим:

$$
A=\frac{1-\beta}{\alpha} ; \quad B=\frac{\beta}{1-\alpha} \leq B
$$

Установим зависимость $m$ от $n, p_{1}, p_{2}, \alpha$ и $\beta$. Для этого подставим (6) значение $\mu$ с учетом (2). В результате получим

$$
\frac{\beta}{1-\alpha}<\frac{p_{2}^{m} q_{2}{ }^{n-m}}{p_{1}^{m} q_{1}{ }^{n-m}}<\frac{1-\beta}{\alpha},
$$

где $q_{1}=1-p_{1}, q_{2}=1-p_{1}$.

Прологарифмируя (7) и выполнив необходимые преобразования, получим выражение вида (8)

$$
\lg \frac{\beta}{1-\alpha}<m \lg \frac{p_{2} q_{1}}{p_{1} q_{2}}+n \lg \frac{q_{2}}{q_{1}}<\lg \frac{1-\beta}{\alpha} .
$$

Используя небольшие преобразования, получим из (8) неравенство относительно $m$.

$$
\frac{\lg \frac{\beta}{1-\alpha}}{\lg \frac{p_{2} q_{1}}{p_{1} q_{2}}}+n \frac{\lg \frac{q_{2}}{q_{1}}}{\lg \frac{p_{2} q_{1}}{p_{1} q_{2}}}<m<\frac{\lg \frac{1-\beta}{\alpha}}{\lg \frac{p_{2} q_{1}}{p_{1} q_{2}}}+n \frac{\lg \frac{q_{2}}{q_{1}}}{\lg \frac{p_{2} q_{1}}{p_{1} q_{2}}} .
$$

В неравенстве (9) обозначим

$$
a=\frac{\lg \frac{1-\beta}{\alpha}}{\lg \frac{p_{2} q_{1}}{p_{1} q_{2}}} ; \quad b=\frac{\lg \frac{\beta}{1-\alpha}}{\lg \frac{p_{2} q_{1}}{p_{1} q_{2}}} ; \quad k=\frac{\lg \frac{q_{2}}{q_{1}}}{\lg \frac{p_{2} q_{1}}{p_{1} q_{2}}},
$$

в результате получим неравенство вида

$$
b+n k<m<a+n k .
$$


На основе неравенства (11) сформулируем рекомендации руководителю поисковоспасательных работ по проведению поиска пропавших людей с помощью КБЛА.

1. Рекомендуется полеты КБЛА прекратить, комплекс мероприятий поисковоспасательных работ в районе поиска прекратить при

$$
m \geq a+n k
$$

2. Рекомендуется полеты КБЛА прекратить, силам и средствам спасения приступить к эвакуации пропавших людей при

$$
m \leq b+n k .
$$

3. Рекомендуется провести еще один дополнительный вылет КБЛА на поиск потерявшихся людей при

$$
b+n k<m<a+n k .
$$

Математическое ожидание количества вылетов КБЛА на поиск потерявшихся людей для принятия рекомендаций 1 или 2 можно определить с использованием выражения (14) [1]:

$$
M[n]=\frac{\lg \frac{1-\alpha}{\beta} \lg \frac{1-\beta}{\alpha}}{\lg \frac{p_{2}}{p_{1}} \lg \frac{q_{2}}{q_{1}}} .
$$

\section{Практическое использование математической модели}

Реализовать предложенную модель можно двумя способами - с использованием и без использования электронно-вычислительных средств.

Первый способ предусматривает на основе представленной математической модели разработку программы расчета потребного количества воздушных разведок КБЛА на поиск потерявшихся людей. Наиболее простым и распространенным средством автоматизированного расчета различных величин являются электронные таблицы MS Exel, входящие в пакет программ Microsoft Offise. Пример использования электронной таблицы MS Exel для расчета потребного количества воздушных разведок КБЛА на поиск потерявшихся людей представлен на рис. 2.

Второй способ позволяет сделать рекомендации руководителю на основе заранее подготовленных графиков. Построение графика осуществляется следующим образом. Строятся две оси координат: ось абсцисс $-n$ количество воздушных разведок КБЛА на поиск потерявшихся людей; ось ординат - $m$ количество воздушных разведок, в результате которых потерявшиеся люди не обнаружены (рис. 3). На основании заданных значений $p_{1}, p_{2}, \alpha$ и $\beta$ строятся параллельные прямые $m_{2}=a+n k$ и $m_{1}=b+n k$. Зона неопределенности находится между этими двумя прямыми. Если в результате воздушной разведки точка с координатами $(n, m)$ лежит выше и левее прямой $m_{2}$, то рекомендуется гипотеза $H_{2}$ - полеты КБЛА прекратить, комплекс мероприятий поисково-спасательных работ в районе поиска прекратить. В случае попадания точки с координатами $(n, m)$ правее и ниже $m_{l}$ рекомендуется гипотеза $H_{l}$ - полеты КБЛА прекратить, силам и средствам спасения приступить к эвакуации пропавших людей. В случае попадания 


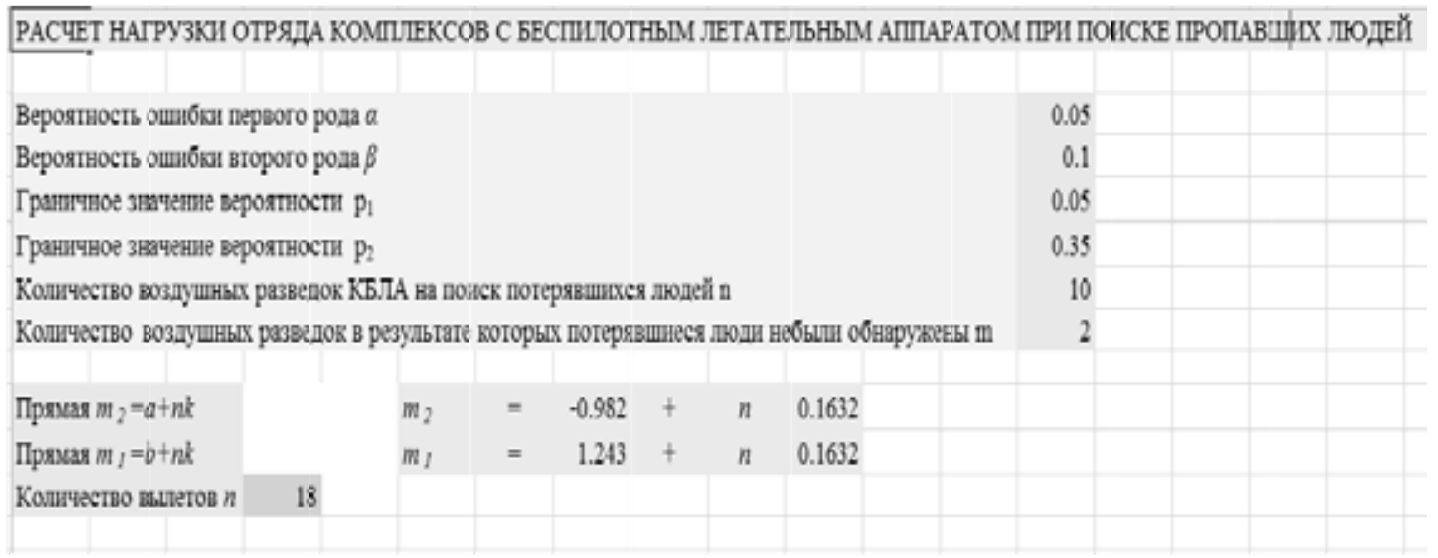

Рис. 2. Фрагмент использования электронной таблицы MS Exel для расчета нагрузки отряда КБЛА при поиске пропавших людей

Fig. 2. Fragment of using MS Excel spreadsheet for calculation loads of KBLA squad when searching for missing people

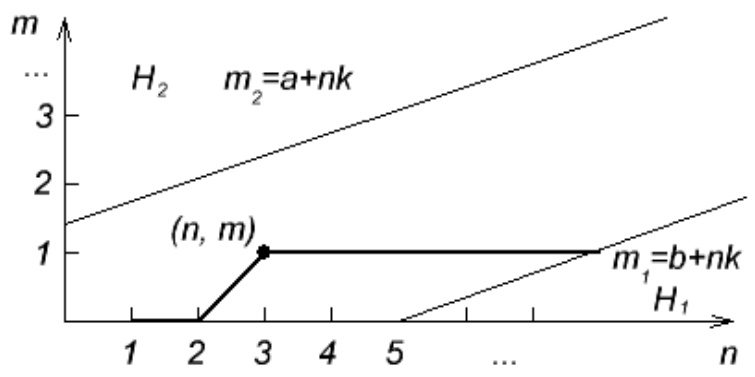

Рис. 3. Определение количества вылетов КБЛА с помощью графика

Fig. 3. Determination of the number of departures KBLA with graphics

точки с координатами $(n, m)$ между прямыми $m_{2}$ и $m_{1}$ рекомендуется поиск пропавших людей с использованием КБЛА продолжить. Количество вылетов для принятия решения определяется по точке пересечения прямой $m_{1}$ с прямой, проведенной через точку с координатами $(n, m)$, параллельной оси $n$.

Реализация графического метода. Руководитель поисково-спасательных работ по поиску потерявшихся людей определяет предельно допустимое число разведок $(n)$ на поиск потерявшихся людей КБЛА. Указывает полезную нагрузку КБЛА, с помощью которой будет осуществляться поиск людей, допустимые значения ошибок 1-го и 2-го родов ( $\alpha$ и $\beta)$. Штаб поисковоспасательных работ готовит рекомендации руководителю для принятия решения. Для этого исходя из характеристик полезной нагрузки КБЛА на воздушную разведку определяют $p_{1}, p_{2}$. Пусть $p_{1}=0,05, p_{2}=0,35, \alpha=0,05, \beta=0,1$. На основе параметров $p_{1}, p_{2}, \alpha$ и $\beta$ с использованием (10), (12), (13) рассчитывают и строят прямые $m_{2}=1.24-0,17 n$ и $m_{1}=-0,98-0,17 n$.

Далее осуществляется последовательная проверка результатов наблюдений. Допустим, что при выполнении первой воздушной разведки в заданном районе пострадавшие не обнаружены. Этому соответствует точка 1 на оси $0 n$. Как видно на рис. 3 , необходимо провести сле-

$$
-829-
$$


дующее разведывательное мероприятие. Предположим, что второе и третье мероприятия дали также неблагоприятный исход (точки 2, 3 на оси $0 n$ ). Нахождение точек в зоне неопределенности свидетельствует о необходимости продолжения разведывательных мероприятий. При неблагоприятном, допустим, исходе четвертого мероприятия также нельзя рекомендовать ни гипотезу $H_{1}$, ни гипотезу $H_{2}$. Подобным образом действуют до тех пор, пока ломаная кривая не пересечет линий $m_{2}$ или $m_{1}$. На рис. 3 показан пример последовательного проведения мероприятий, когда только после восемнадцати мероприятий оказалось возможным рекомендовать конкретную гипотезу и вариант решения.

\section{Выводы}

1. На основе метода последовательного анализа предложена математическая модель расчета нагрузки отряда комплексов с беспилотными летательными аппаратами при выполнении поиска пропавших людей в труднодоступных районах.

2. Модель расчета является объективной основой выработки штабом поисковоспасательных работ предложения для принятия решения руководителем продления или прекращения мероприятий поиска пропавших людей в труднодоступных районах.

3. Предложены практические варианты использования модели штабом поисковоспасательных работ поиска пропавших людей в труднодоступных районах.

\section{Список литературы}

[1] Волгин Н.С. Исследование операций. Санкт-Петербург: ВMA, 1999. 366 с. [Volgin N.S. Operations research. Saint-Petersburg: Military Naval Academy, 1999. 366 p. (in Russian)].

[2] Моисеев В.С. Прикладная теория управления беспилотными летательными аппаратами, Казань: ГБУ «Республиканский центр мониторинга качества образования» (Серия «Современная прикладная математика и информатика», 2013. 768 c. [Moiseev V.S. Applied management science unmanned aerial. Kazan, "Republican center of education quality monitoring" (Series "Modern applied mathematics and computer science", 2013. 768 p. (in Russian)].

[3] Студитский А.С. Исследование и разработка многофункиионального оптикоэлектронного средства наблюдения и разведки, автореф. дис...канд. тех. наук. М., 2013. 21 с. [Studitsky A.S. Research and development of multifunctional optical-electronic surveillance and intelligence. dis...kand. of technical Sciences. Moscow, 2013. 21 C. (in Russian)]. 